\title{
MINIMIZAÇÃO DO IMPACTO AMBIENTAL COM A TÉCNICA DA RETIFICAÇÃO CILÍNDRICA EXTERNA DE MERGULHO DE CERÂMICAS AVANÇADAS COM A UTILIZAÇÃO DA MÍNIMA QUANTIDADE DE LUBRIFICANTE (MQL) COM ADIÇÃO ÁGUA
}

\author{
Edmilson Antônio Sarni ${ }^{1}$ \\ Eduardo Carlos Bianchi ${ }^{2}$ \\ Paulo Roberto Aguiar ${ }^{3}$ \\ Anselmo Eduardo Diniz ${ }^{4}$
}

Bruno Canton ${ }^{5}$

RESUMO: Os fluidos de corte foram introduzidos nos processos de usinagem com a finalidade de melhorar as características de os processos tribológicos que estão sempre presentes nas superfícies de contato entre a ferramenta e a peça. Devido à multiplicidade de efeitos negativos do corte os fluidos, os resíduos produzem sobre a humanidade e o nosso meio ambiente, na produção moderna, tem havido uma crescente atenção com os cuidados para se selecionar os fluidos de forma eficiente que, além de eficiente deve ser compatível com o ambiente. Além dos requisitos habituais tribológicos de corte, os fluidos devem satisfazer as exigências do ambiente e atender a legislação ambiental imposta pelo Estado ou internacional ISO 14000. Dentre as alternativas, destaca-se a usinagem a seco e a utilização da mínima quantidade de lubrificação (MQL). Este último pode ser utilizado também com adição de água e, consequentemente, consumindo um volume menor de fluido de corte. Este trabalho pretende analisar o comportamento da técnica da MQL com adição de água no processo de retificação de cerâmicas avançadas, assunto pouco

\footnotetext{
${ }^{1}$ Mestre em Engenharia Mecânica pela UNESP, Bauru. edmilsonsarni@hotmail.com

${ }^{2}$ Engenheiro Mecânico, UNESP, Professor Titular. bianchi@feb.unesp.br

${ }^{3}$ Engenheiro Eletricista, UNESP, Professor Titular. aguiarpr@feb.unesp.br

${ }^{4}$ Engenheiro Mecânico, UNICAMP, Professor Titular. anselmo@unicamp.br

${ }^{5}$ Aluno de Engenharia Mecânica, UNESP, Bolsista FAPESP. ra711497@feb.unesp.br
} 


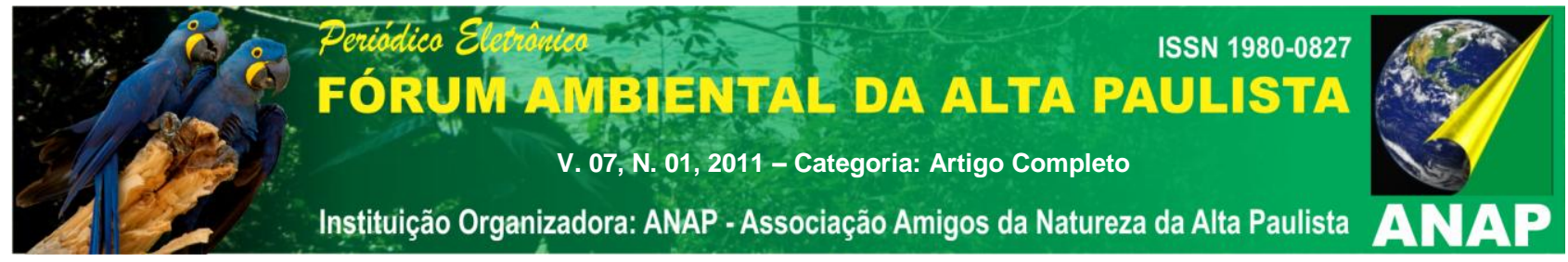

divulgado na literatura formal. Este estudo foi feito através da análise da avaliação do comportamento rugosidade do material retificado. Pela avaliação dos resultados obtidos, foi possível avaliar a técnica da MQL com água, interpretando-a como um método alternativo de usinagem menos agressivo ao meio ambiente, já que houve melhoria consistente da rugosidade do material pela técnica da MQL tradicional para a MQL com adição de água e com a limpeza da superfície de corte do rebolo.

Palavras-chave: Meio ambiente. Preocupação ambiental. Uso do fluido de corte. Cerâmicas avançadas.

\section{INTRODUÇÃO}

A retificação é um processo de fabricação em que se utiliza uma grande quantidade de fluído de corte, cujas funções são: lubrificação, reduzindo deste modo a geração de calor; refrigeração, eliminando o calor gerado; retirada do cavaco na zona de corte; proteção da máquina-ferramenta e da peça à corrosão atmosférica, entre outros.

A energia no processo de retificação é utilizada na formação do cavaco, deformações e atrito. Nas temperaturas de pico, o material da peça chega a aproximar-se da temperatura de fusão mas, como o tempo de contato rebolo/peça é extremamente reduzido, tais temperaturas estão localizadas nos planos de cisalhamento dos cavacos e o cavaco não chega a fundir, porém ocasiona variações metrológicas na qualidade final do produto (DHAR et al, 2007; LEE et al, 2002).

O efeito das elevadas temperaturas atingidas durante o processo de retificação deve ser evitado. Apesar das muitas vantagens encontradas na utilização de fluidos de corte durante a usinagem, estes apresentam desvantagens econômicas e ecológicas que tem feito com que novas pesquisas, buscando a diminuição de fluidos ou até mesmo a eliminação deste, sejam realizadas (SAHM, D.; SCHNEIDER, T., 1996).

Para que a utilização de fluídos de corte seja minimizada, duas técnicas têm sido intensamente experimentadas: o corte completamente sem fluído (corte a seco) e o corte com MQL.

O método da MQL pode ser descrito como pequenas gotículas de óleo que são encontradas em meio a um jato de ar comprimido. Essas gotículas são levadas pelo jato de ar diretamente à superfície de trabalho garantindo a refrigeração e lubrificação necessária (SAHM, D.; SCHNEIDER, T., 1996).

$\mathrm{Na}$ retificação de aços endurecidos, os valores de rugosidade e desgaste diametral do rebolo são significativamente menores com o uso da técnica da MQL, assim como a 


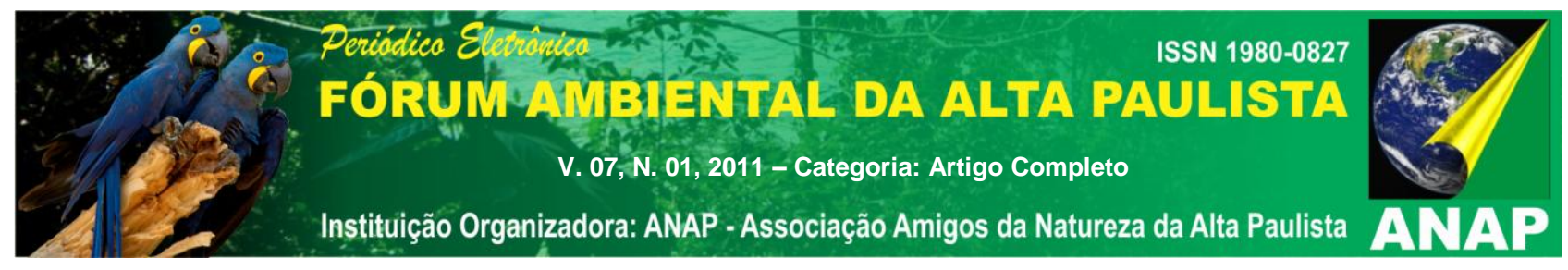

força tangencial de corte e energia específica, demonstrando a boa capacidade de lubrificação da técnica da MQL (SOKOVIC, 2001).

A mínima quantidade de lubrificante com água, conhecida como Oil-on-Water (OoW), apresenta uma alta capacidade de refrigeração já que às gotículas de água envoltas pela camada de óleo que evaporam facilmente nas superfícies da peça e da ferramenta e refrigeram as superfícies devido à sua sensibilidade e latência ao calor. Foi verificado que a MQL com gotas de água, proporciona uma boa lubrificação se o lubrificante utilizado for adequado, como éster sintético. A MQL com éster sintético, sem água, proporciona resultados inferiores (TAWAKOLI et al, 2007).

O conceito das gotículas de água envoltas por uma camada de óleo pode ser observado na figura (1).

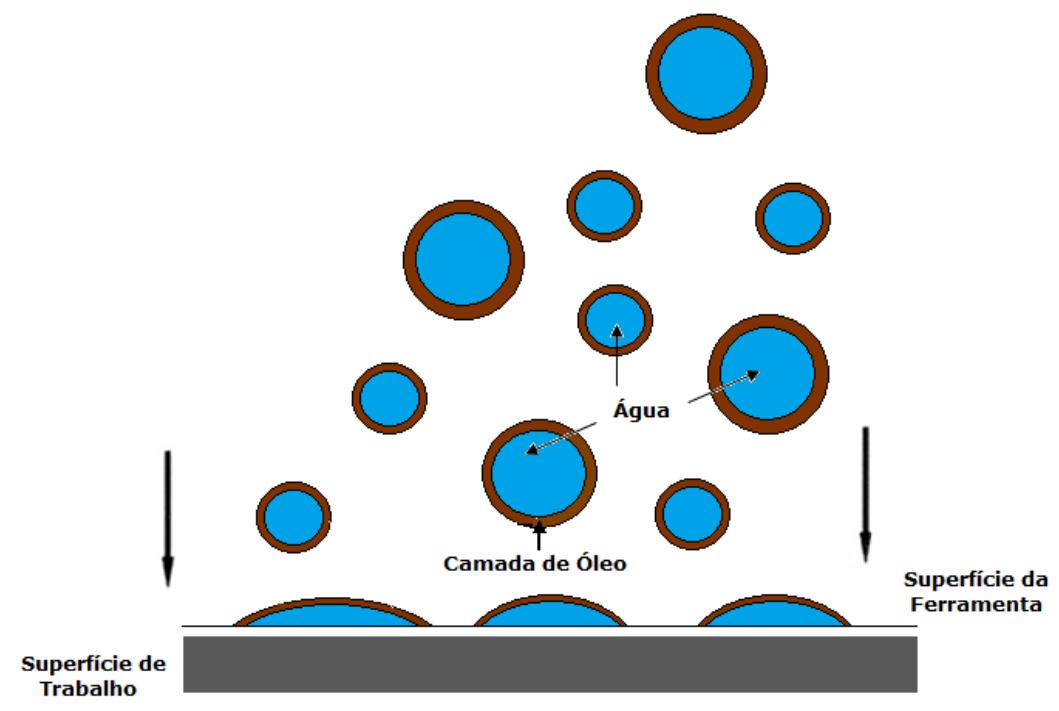

Figura 1 - Conceito das gotículas de água envoltas pela camada de óleo (TAWAKOLI et al, 2007)

A capacidade de refrigeração gerada devido às gotículas de água não é importante somente para a precisão dimensional, mas também para evitar alguns efeitos entre a ferramenta e a superfície de trabalho como, por exemplo, a adesão. Ainda afirmam que a MQL com gotas de água, tem uma grande capacidade de remoção de calor porque as gotas de água, que transportam o óleo, evaporam facilmente devido ao calor latente da mudança de fase. Essa capacidade de resfriamento é importante para a precisão 


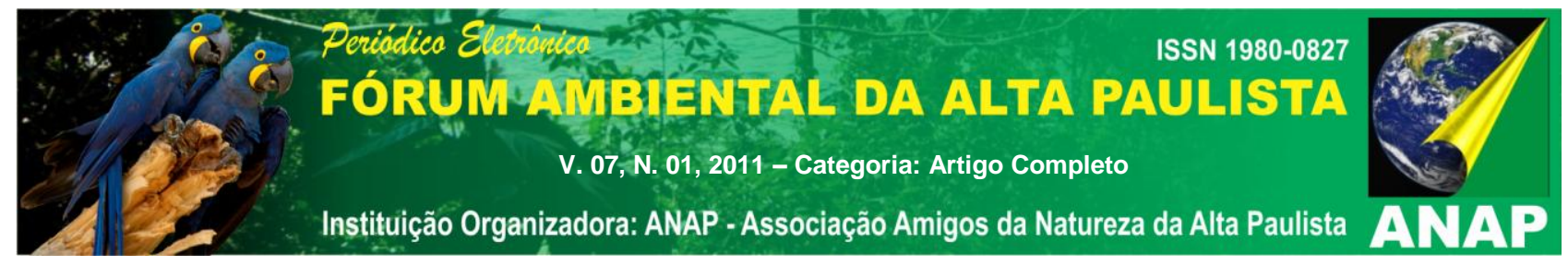

dimensional e para os fenômenos tribológicos entre a superfície da ferramenta e do trabalho, tais como a adesão.

As cerâmicas avançadas têm sido usadas para fabricação de peças que requerem uma qualidade especial única originária da combinação das propriedades particulares de diversos materiais. Sua aplicação inclui rolamentos de precisão para uso nas indústrias nucleares, componentes automotivos (sensores, isoladores, catalisadores, pistões, pastilhas, válvulas), peças de desgaste, refratores, entre outros. Porém o custo da usinagem de cerâmicas é o principal obstáculo na produção em larga escala, podendo chagar a 50\% do custo total de fabricação. Portanto, a preocupação com o meio ambiente e com a saúde do trabalhador tornaram imprescindível à realização de pesquisas sobre formas alternativas de lubrificação no processo de retificação, com a expectativa de utilizar-se o mínimo possível de fluido de corte nas operações de usinagem. Desta forma, a mínima quantidade de lubrificante (MQL) é uma alternativa plausível e a possibilidade do uso deste com água faz com que o volume de óleo utilizado seja mínimo. O objetivo deste trabalho é apresentar os resultados obtidos de rugosidade em cerâmicas avançadas e desgaste de rebolos diamantados utilizando o processo de retificação cilíndrica de mergulho com três formas de lubri-refrigeração: convencional, MQL tradicional e MQL com adição de água.

As condições de usinagem e materiais utilizados para a realização dos ensaios foram: Retificação cilíndrica de mergulho; rebolo diamantado D140 N100V, retificadora SulMecânica (RUAP $515 \mathrm{H}-\mathrm{CNC}$ ), velocidade de corte $30 \mathrm{~m} / \mathrm{s}$, profundidade de corte 0,1mm/volta, lubri-refrigeração: convencional e MQL, fluido de corte (convencional) ROCOL 4847 Ultracut 370 com 5\% de concentração, vazão do óleo (MQL) de 100ml/h, fluido de corte (MQ) ROCOL Cleancut, pressão do ar de 8 bar, material do corpo de prova, alumina comercial $(\mathrm{De}=54 \mathrm{~mm}, \mathrm{Di}=30 \mathrm{~mm}$, e $=4 \mathrm{~mm})$, dressador do tipo conglomerado, profundidade de dressagem $(\mathrm{ad})=0,01 \mathrm{~mm}$. Foram utilizados três diferentes formas de lubri-refrigeração, sendo estes o método convencional, o método MQL tradicional e o método MQL com água (OoW) nas proporções 1:1, 1:3 e 1:5 (uma parte de óleo diluído em uma, três e cinco partes de água). Foi utilizado um sistema de limpeza do rebolo por ar comprimido com um bocal na posição tangente em relação à superfície de corte do rebolo. Isso garantiu a limpeza da superfície de corte do rebolo pela remoção dos cavacos que aderem à superfície de corte do rebolo na forma de "borra". 


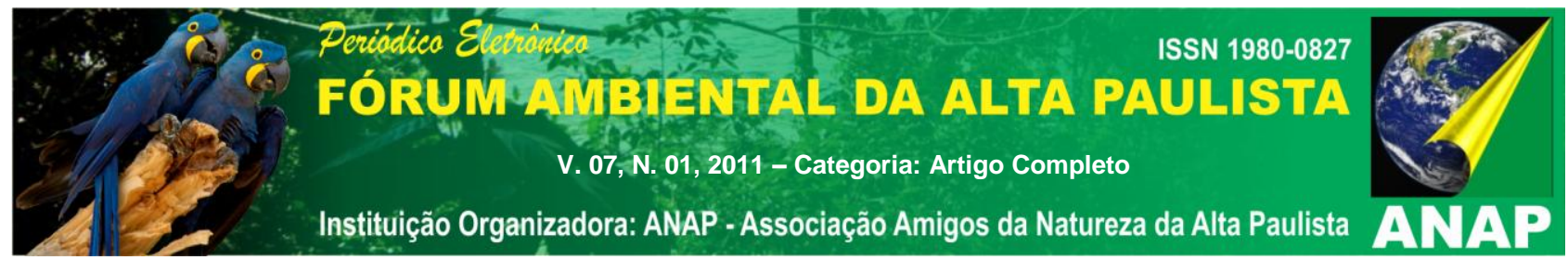

Antes da realização de cada ensaio, o rebolo era dressado, permitindo que para todos os ensaios, a ferramenta abrasiva apresentasse as mesmas condições iniciais. Após a realização da dressagem o corpo-de-prova cerâmico era preso em um mandril e fixado entre pontas na retificadora cilíndrica. Posteriormente realizava-se a normalização da peça, ou seja, em que apenas um mergulho do rebolo sobre o corpo-de-prova era feita a uniformização do diâmetro externo deste antes de se iniciar os ensaios. Para cada ensaio foram utilizados cinco corpos de prova de cerâmica.

Para cada dressagem eram realizados dois ensaios, um do lado esquerdo e um do lado direito do rebolo. Utilizando-se toda largura do rebolo, realizava-se então a impressão do rebolo em tarugos de aço e posteriormente dressava-se novamente o rebolo para possibilitar outros ensaios. O perfil marcado no tarugo era utilizado para a medição do desgaste do rebolo.

Antes de realizar os ensaios convencionais, a concentração do fluido era avaliada através de um refratômetro manual de bolso, marca ATAGO, modelo N-1 E, e corrigida, se necessário, com adição de fluido de corte ou água, dependendo do valor obtido.

Os valores de rugosidade foram obtidos através da utilização do rugosímetro marca Taylor Hobson, modelo Subtronic 3+, e os valores de circularidade através do circularímetro marca Taylor Hobson, modelo Tayround 31C.

A cada ensaio ajustava-se a velocidade de mergulho do rebolo ou o método de lubri-refrigeração para atender às condições desejadas.

\section{DESENVOLVIMENTO}

A Figura 2 apresenta os valores de rugosidade media, com as dispersões, medidos após a retificação das peças.

O observa-se que o método convencional foi o que apresentou os menores valores de rugosidade para todas as velocidades de avanço, devido à melhor remoção de cavaco da zona de corte proporcionada pela refrigeração convencional.

O método tradicional da MQL apresentou valores médios cerca de 65\% maior que o convencional, devido à formação de uma "borra" parcial de óleo/cavaco que permanece nos poros do rebolo e que é de difícil remoção. 

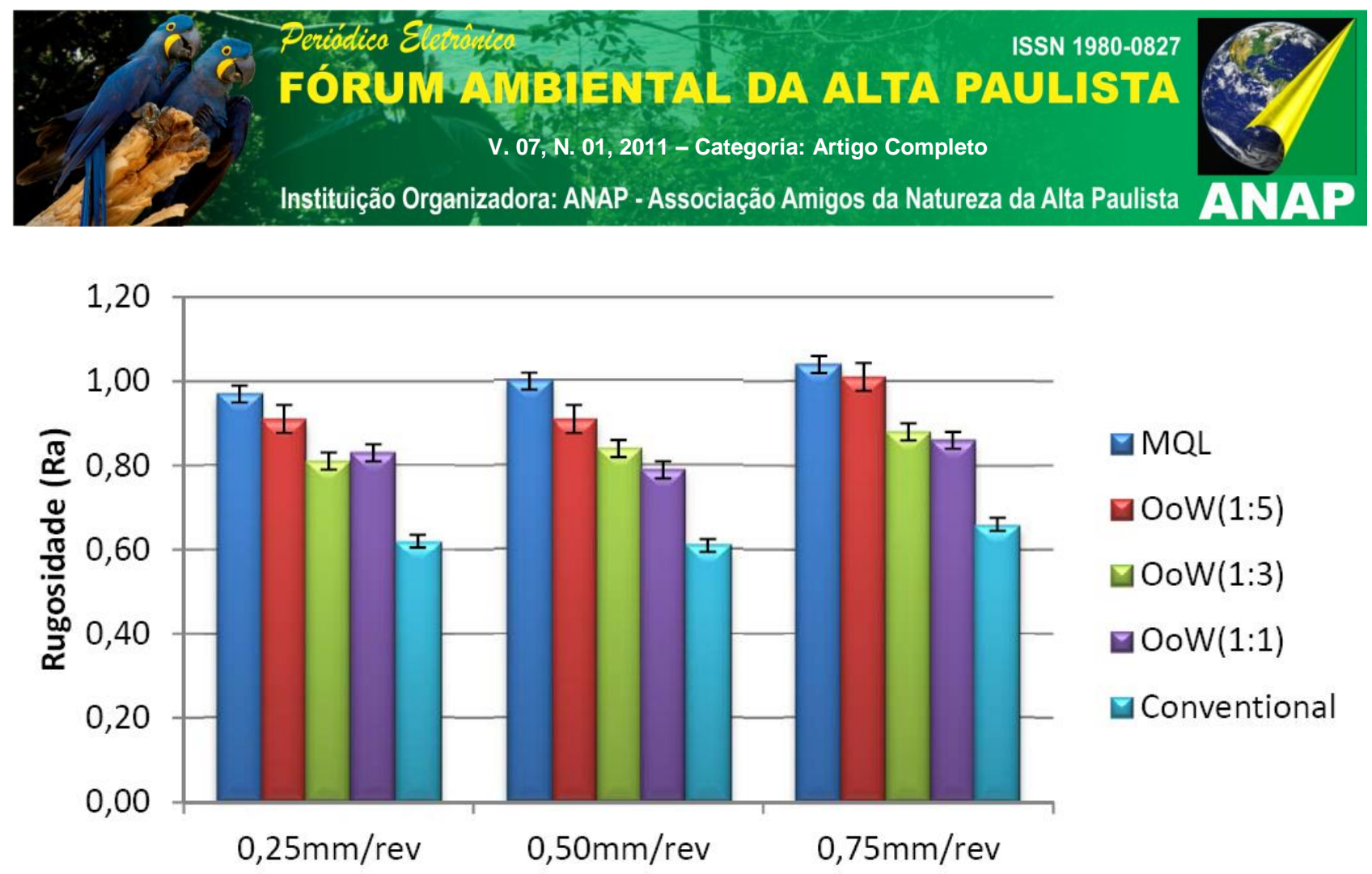

Figura 2 - Valores médios de rugosidade, com as respectivas dispersões.

Os cavacos presentes nesta "borra" riscam a peça, causando um aumento da rugosidade. Parte da "borra" foi retirada pelo sistema de limpeza da superfície de corte por ar comprimido, o que proporciona resultados melhores no acabamento da peça se comparados aos utilizados sem este sistema de limpeza.

Porém observa-se que os métodos com adição de água obtiveram valores menores que a MQL tradicional. O OoW (1:1) foi o que obteve a tendência de melhor resultado, cerca de $35 \%$ maior que o convencional e $20 \%$ menor que a MQL tradicional. O melhor desempenho da mistura ar-óleo-água quando comparado ao ar-óleo na MQL ocorre pelo fato que a menor viscosidade da água faz com que a "borra" cavaco-fluido seja menos aderente ao rebolo e, consequentemente, mais fácil de ser retirada dos poros do rebolo. Os cavacos presos aos poros do rebolo riscam a peça, aumentando sua rugosidade. Neste caso, deve-se observar a influência da melhor capacidade de refrigeração da água em comparação ao óleo puro do MQL tradicional. Entretanto, ao aumentar a proporção de água, observa-se a tendência da elevação dos valores de rugosidade, o que ocorre devido à perda de capacidade de poder lubrificação, já que a proporção de óleo é menor. Assim, quanto mais óleo e menos água na mistura, mais fácil é a retirada dos cavacos dos poros, porém pior é a lubrificação das interfaces cavacoferramenta. Então, a inserção de água na mistura tem um efeito positivo na rugosidade (facilidade de limpeza do rebolo) e um efeito negativo (menor lubrificação). O fato da MQL 


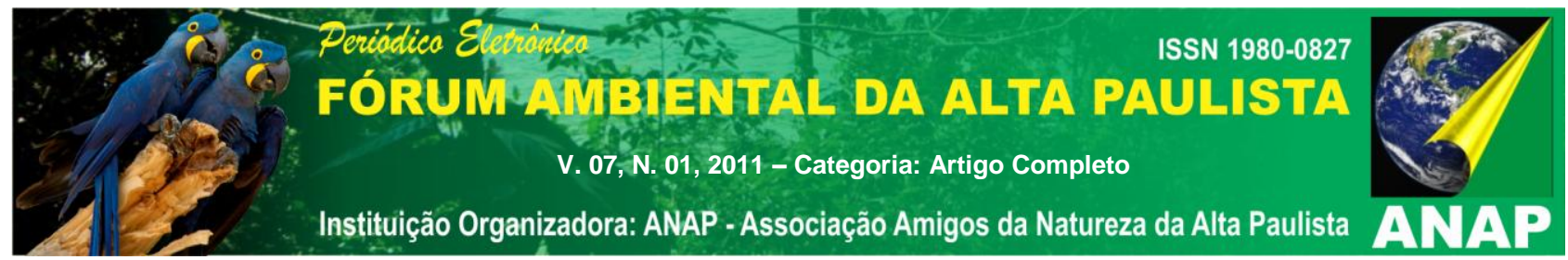

convencional ter gerado maior rugosidade que a MQL com água, indica que o primeiro fator foi preponderante. Porém, um ponto é contraditório: analisando-se somente as MQLs com água, quanto mais água na mistura, pior é a rugosidade. Vê-se na figura 3 que quando se teve as proporções 1:1 e 1:3 os valores de rugosidade foram similares, mas quando se aumentou a proporção de água (OoW = 1:5) a rugosidade aumentou. Isso ocorreu devida a saturação da capacidade de limpeza do rebolo. Em outras palavras, o aumento da quantidade de água da mistura não aumentou a capacidade de limpeza do rebolo e somente diminuiu a capacidade de lubrificação da mistura. Com isso, obtiveramse os piores valores de rugosidade dentre aqueles obtidos com a MQ com água nos ensaios em que foi utilizada grande proporção de água (1:5).

Para se verificar a capacidade de limpeza da superfície de corte no processo de retificação, são apresentados na figura 3 os resultados obtidos para a rugosidade média $\mathrm{Ra}$, referente à comparação entre as condições de lubri-refrigeração convencional e as condições utilizando a técnica do MQL. Os valores de rugosidade apresentados são médias de 5 medições de rugosidade em posições diferentes nos corpos de prova, para cada condição de lubri-refrigeração.

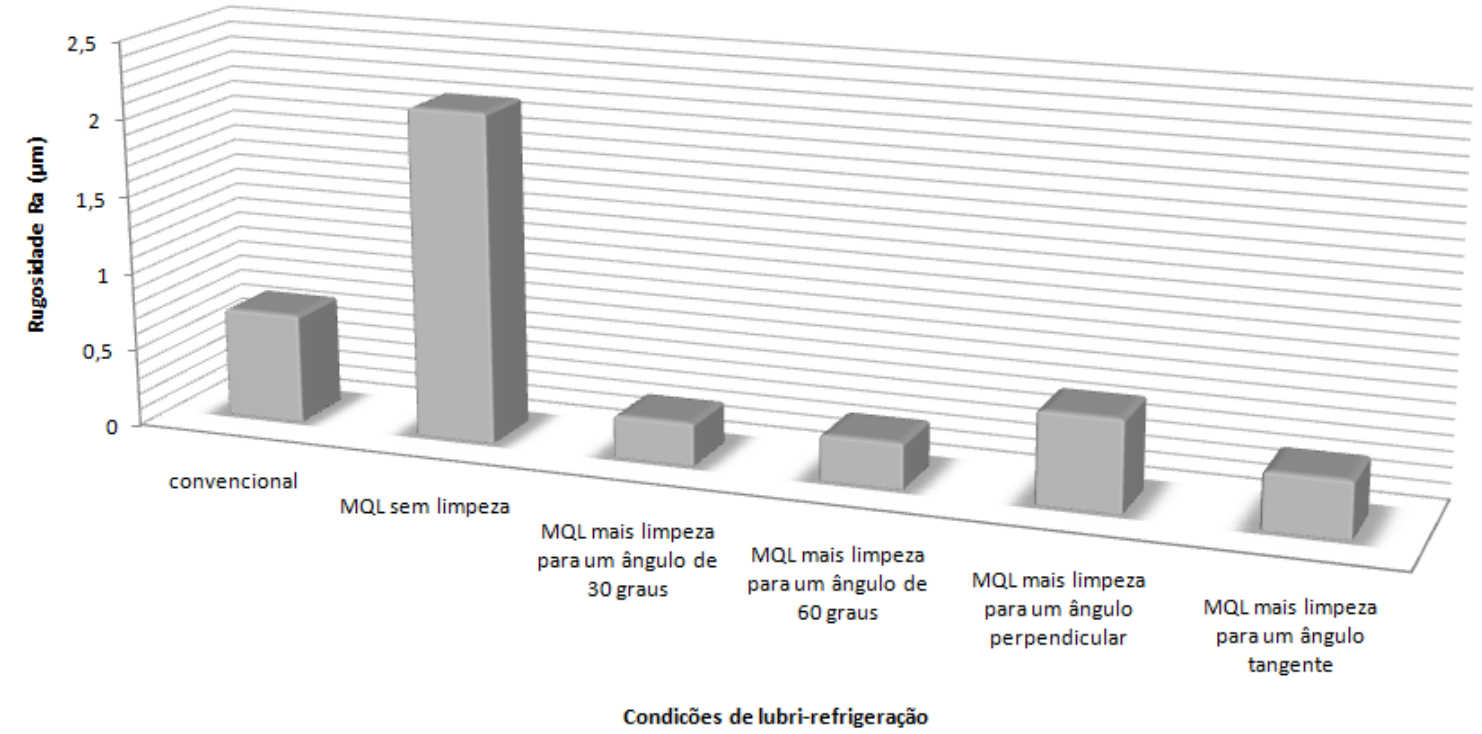

Figura 3 - Resultados de rugosidade para as diferentes condições de lubrirefrigeração.

Por meio de uma análise geral dos resultados de rugosidade, a maioria dos valores está abaixo de 1,6 $\mu \mathrm{m}$, valor máximo para uma peça retificada (Diniz et al, 2001) . 


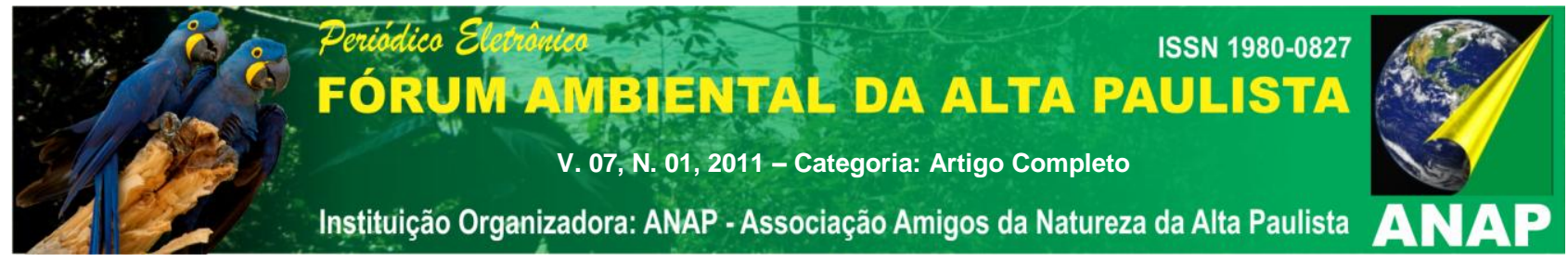

Assim, analisando-se estes resultados, verifica-se que todas as condições de limpeza foram satisfatórias, pois os valores obtidos de rugosidade média ficaram abaixo do obtido até mesmo com a condição convencional e muito abaixo daquele obtido com o MQL sem limpeza. Além disso, a condição de limpeza com a incidência perpendicular do jato de ar comprimido se igualou ao convencional, praticamente.

De uma forma geral, a condição MQL com limpeza para um ângulo de 30 graus foi a melhor condição, pois apresentou a menor rugosidade, muito abaixo do valor obtido com a condição convencional.

Com relação à eficiência do sistema de limpeza por meio do ar comprimido, essa é uma função da velocidade periférica do rebolo e do ângulo de incidência do ar, já que a pressão e vazão do sistema foram mantidas constantes. Isso ocorre, pois o fenômeno da limpeza se dá pela soma vetorial dessas componentes de velocidades, a periférica do rebolo e a do ar comprimido, sendo esta última depende do ângulo de incidência. Assim, quanto mais eficiente essa combinação de velocidades, será gerada uma resultante que transferirá uma maior quantidade de movimento à "borra", promovendo sua maior eliminação. Assim, de forma geral, o MQL com limpeza para uma inclinação de 30 graus foi a melhor combinação de velocidades.

Apesar de a condição convencional ter um maior fluxo de fluido e eliminar os cavacos da zona de corte mais eficientemente em comparação ao MQL sem limpeza, como se descreve na literatura, a utilização da limpeza em todas as velocidades de mergulho fez com que a rugosidade se tornasse próxima ou menor à rugosidade obtida com a técnica convencional. Com isso, pode-se afirmar que mesmo na convencional, os cavacos ainda acabam se alojando nos poros do rebolo, o que é natural do processo de retificação, mas na limpeza esta proporção de cavacos nos poros ficou ainda menor, pois o ar do sistema de limpeza age diretamente, como único e exclusivamente na eliminação da "borra" de óleo da superfície de corte do rebolo e conseqüentemente os cavacos aderidos nos poros, que evitam riscar a superfície da peça sendo usinada, melhorando, assim, sua rugosidade.

\section{CONCLUSÕES}

O uso da técnica de lubri-refrigeração MQL associada a um jato de ar comprimido para limpeza da superfície de corte do rebolo com ângulo de incidência de 30 graus, 
propiciou melhores resultados em todas as variáveis analisadas, quando comparados a lubri-refrigeração convencional.

A drástica redução da quantidade de fluído alcançada, a melhoria da rugosidade e circularidade, e a diminuição do desgaste do rebolo, com o uso desta técnica, MQL mais a limpeza, indicam que este aprimoramento das condições de lubri-refrigeração na retificação pode reduzir os insumos e os impactos ambientais e à saúde dos trabalhadores, tornando este processo de fabricação mais limpo, rápido e econômico.

A limpeza refeita na superfície de corte do rebolo mostrou-se altamente eficiente.

Com a técnica de MQL com adição de água e limpeza da superfície de corte do rebolo os ganhos tecnológicos são relevantes com a maior preservação do meio ambiente.

\section{AGRADECIMENTOS}

Manifestamos nossos agradecimentos à FAPESP pelo apoio financeiro.

\section{REFERÊNCIAS}

DHAR, N., ISLAM, S. and KAMRUZZAMAN, M., 2007, "Effect of Minimum Quantity Lubrication (MQL) on Tool Wear, Surface Roughness and Dimensional Deviation in Turning AISI-4340 Steel”, G.U. Journal of Science, vol. 20, pp. 23-32.

LEE, S.W., LEE, Y.C, JEOND, H.D. and CHOI, H.Z., 2002, "The Effect of High Pressure Air Jet on Form Accuracy in Slot Grinding", Journal of Materials Processing Technology, vol. 128 , pp. $67-72$.

SAHM, D., SCHNEIDER, T., 1996, “The production without coolant is interesting and must be more known", Machines and Metals Magazine (367), 38-55.

SOKOVIC, 2001, "Ecological aspects of the cutting fluids and its influence on quantifiable parameters of the cutting processes", Journal of Materials Processing Technology, vol. 109, pp. 181-189. 


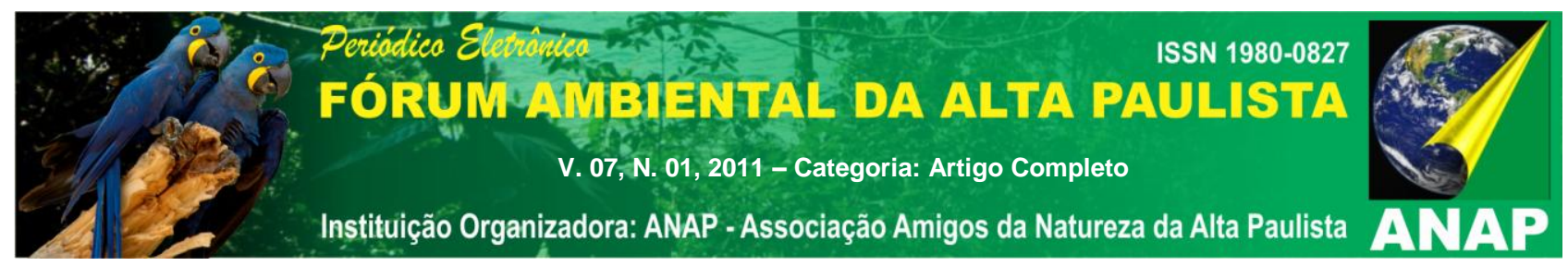

TAWAKOLI, T., WESTKAEMPER E., RABIEY M., 2007, "Dry grinding by special conditioning", International Journal of Advanced Manufacturing Technology, 33:419-424. 